\title{
SISTEM INFORMASI PENGADAAN \\ BAHAN PRODUKSI BETON SIAP PAKAI (READYMIX) PADA PT. SCG READYMIX INDONESIA PLANT CILEGON
}

\author{
Waliadi Gunawan $^{1}$, Yuli Setyaningsih ${ }^{2}$ \\ Fakultas Ilmu Komputer Universitas Banten Jaya \\ Jl. Ciwaru Raya II No. 73 Warung Pojok Kota Serang Banten \\ E-mail: waliadigunawan@unbaja.ac.id ${ }^{1}$, yulisetyaningsih@unbaja.ac.id ${ }^{2}$
}

\begin{abstract}
In the system of readymix concrete production material procurement at PT. SCG Indonesia Readymix Plant Cilegon, the company was still conduced by manual system. It used filing system that stored in the production division. The entry system used the form that submitted directly, therefore in making report, it needed inefficient time and created difficulties for the clerk to input the data manually in receiving production material. If the company required the data about material production, they must seek the data from the stack of existing archive. Besides that, the report generated less efficient because in the recording the data was conducted by employee that still used system manually. Therefore, sometime the result of report contained some errors. To overcome the existing problems, it is necessary to use the computer based of production materials procurement information system. The aims were 1) to facilitate the procurement of material for the production process, 2) to make easier for the employees to find out and to enter the necessary data of production materials procurement, 3) to create the effective and efficient work, and 4) to use in making report of production material procurement quickly and easily.
\end{abstract}

Keywords: information, procurement, system.

\section{PENDAHULUAN}

Perkembangan dunia informasi saat ini semakin cepat memasuki berbagai bidang sehingga banyak perusahaan meningkatkan usahanya terutama dalam bidang ilmu pengetahuan dan teknologi, sebagai modal untuk kemajuan perusahaan, karena ilmu pengetahuan dan teknologi merupakan kekuatan untuk kemajuan dunia usaha.

Sekarang ini pengoperasian pabrik industri kebanyakan sudah menggunakan sistem kontrol otomatis. Guna memenuhi berbagai persyaratan seperti : faktor keamanan, spesifikasi produk, keramahan lingkungan, kondisi operasi, dan keuntungan optimasi, maka dibutuhkan suatu pengontrol untuk mengendalikan variabel-variabel proses yang dapat meminimalkan pengaruh gangguan, menjamin kestabilan dan mengoptimalkan kinerja proses. 
Salah satunya dengan sistem Distributed Control System (DCS) dengan tujuan menghasilkan suatu produk yang memiliki nilai ekonomis dengan menggunakan berbagai sumber daya dan berorientasi terus menerus produksi seperti : industri semen, makanan, minuman, kimia, pembangkit listrik, obatobatan, besi, baja dan kertas.

Sebagaimana layaknya perusahaan yang sedang berkembang, Pt. SCG Readymix Indonesia tengah berupaya menjaga dan meningkatkan mutu produksi beton siap pakai yang dipasarkan pada konsumennya. Hal tersebut dapat dicapai jika adanya sumber daya diantaranya sumber daya manusia, mesin dan cara kerja (Man, Machine, and Methode).

Berdasarkan hal tersebut pemberdayaan sumber daya manusia patut mendapatkan perhatian yang serius guna kelancaran proses kerja dan produktifitas yang sesuai dengan standarisasi serta tercapainya target perusahaan yang telah ditentukan. Pengadaan bahan produksi beton siap pakai juga dibutuhkan saat kegiatan overhaule, yaitu pengecekan rutin bahan produksi yang dijadwalkan setiap hari oleh operator dan departemen produksi guna menjaga kualitas bahan produksi yang baik.

\section{METODE PENELITIAN}

Untuk mewujudkan maksud penelitian ini, terdapat metode penelitian yang dilakukan langsung pada objek penelitian, data dan keterangan yang dikumpulkan dilakukan dengan cara:

(1) Pengamatan (Observation)

Penulisan melakukan pengamatan untuk mendapatkan data secara umum dengan melihat langsung, mengamati dan mencatat sistem yang sedang berjalan saat ini serta melihat format-format yang dilakukan selama ini.

(2) Wawancara (Interview)

Dalam hal ini penulis melakukan wawancara untuk melengkapi bahan yang sudah ada selama observasi. Penulis melakukan tanya jawab kepada staff atau pegawai Pt. SCG Readymix Indonesia Plant Cilegon yang berkaitan dengan sistem yang sedang berjalan. 


\section{HASIL DAN PEMBAHASAN}

Sistem informasi pengadaan bahan produksi pada PT. SCG Readymix Indonesia Plant Cilegon yang berjalan saat ini di setiap plant-plant belum menggunakan aplikasi yang memudahkan para pegawai untuk mengadakan bahan produksi. Pengecekan bahan produksi masih dilakukan dengan mengecek ke gudang langsung, di catat satu persatu kebutuhan bahan produksi apa saja yang dibutuhkan, lalu data-data kebutuhan bahan produksi dikirim ke kantor pusat karena PT. SCG Readymix Indonesia merupakan perusahaan yang terpusat. Dan yang memesan kebutuhan bahan produksi adalah kantor pusat, sehingga sering terjadi keterlambatan bahan produksi sehingga dapat menghambat proses produksi yang ada.

\section{Desain Modul Tampilan (Screen)}

\section{A. Tampilan Input (Masukan)}

Rancangan Tampilan Login

\section{LOGIN}

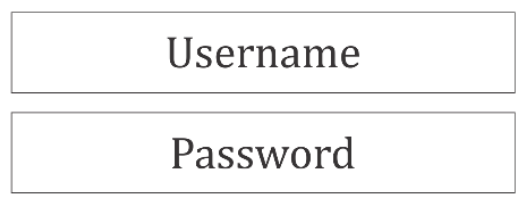

\section{MASUK}

\section{Gambar 1 Rancangan Tampilan Login}

\section{Rancangan Tampilan Menu Utama}

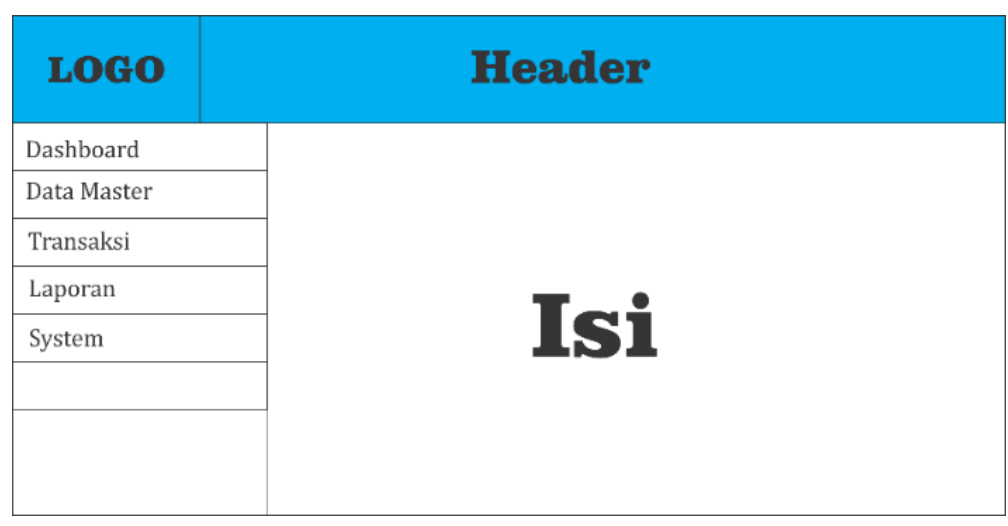

Gambar 2. Rancangan Tampilan Menu Utama 


\section{Rancangan Tampilan Data Barang}

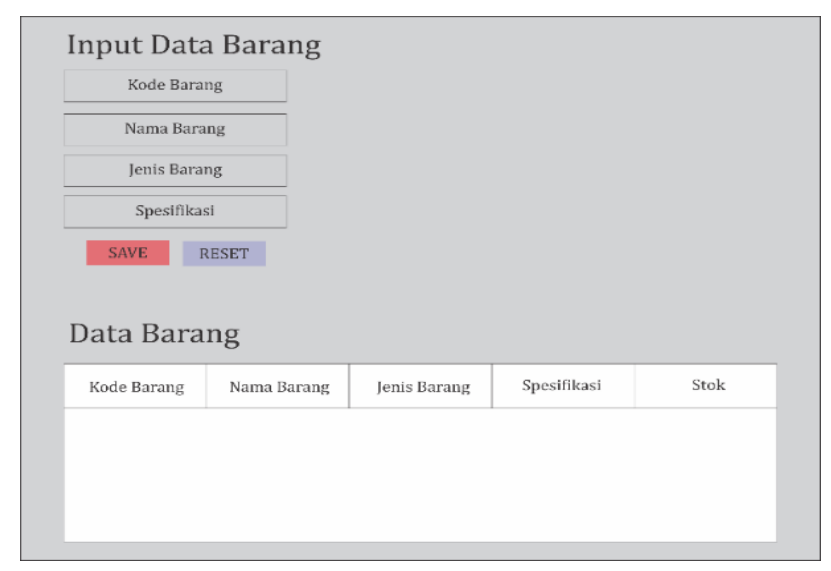

Gambar 3. Rancangan Tampilan Data Barang

\section{Rancangan Tampilan Data Supplier}

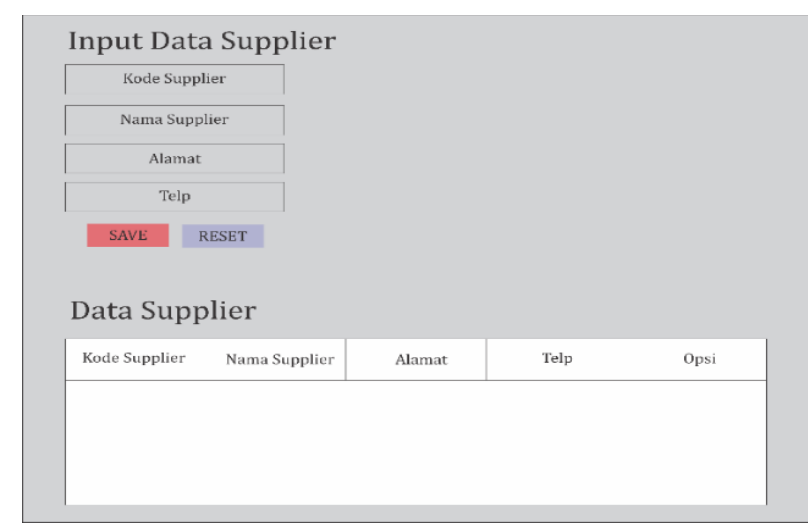

Gambar 4. Rancangan Tampilan Data Supplier

B. Tampilan Proses (Transaksi)

Rancangan Tampilan Barang Masuk

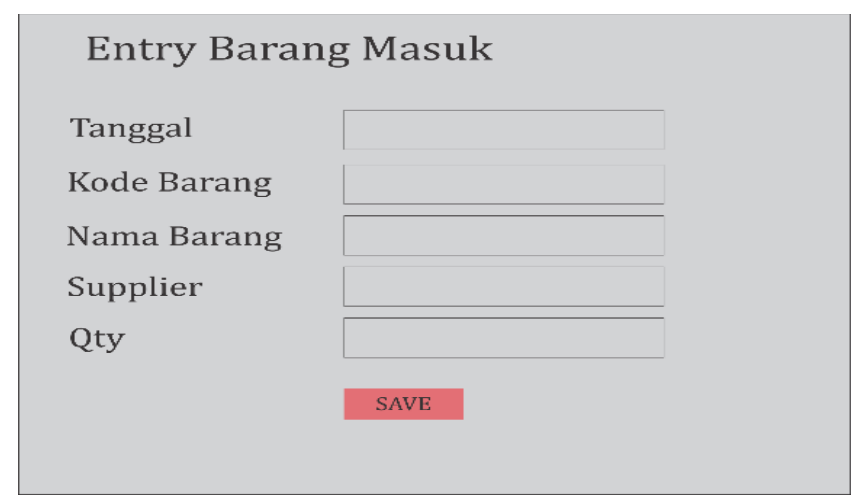

Gambar 5. Rancangan Barang Masuk 


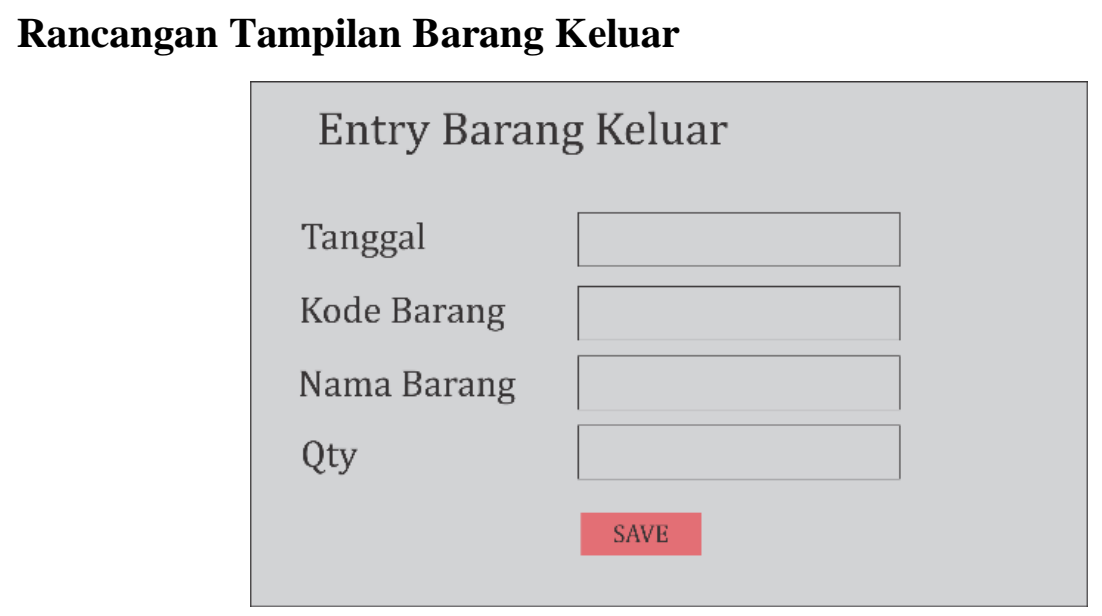

Gambar 6. Rancangan Tampilan Barang Keluar

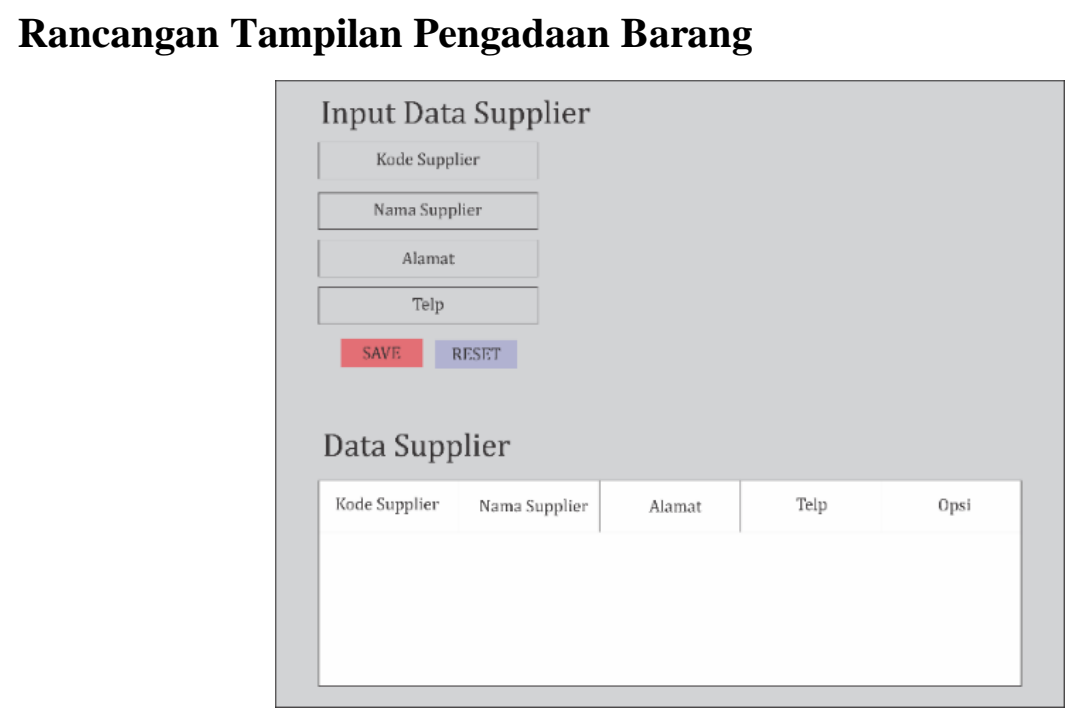

Gambar 7. Rancangan Tampilan Pengadaan Barang

\section{Tampilan Output (Keluaran)}

Rancangan Tampilan Laporan Barang Masuk dan Keluar

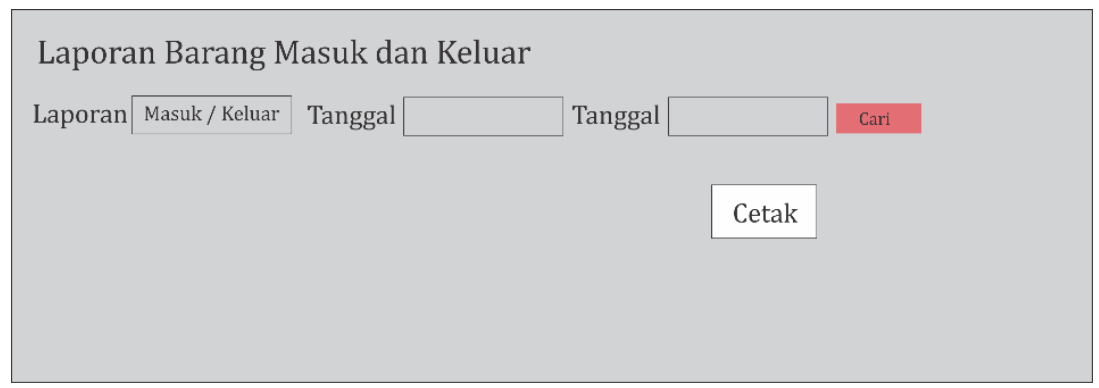

Gambar 8. Rancangan Tampilan Laporan Barang Masuk dan Keluar 


\section{Prosedur Operasional (Manual Book)}

Pengoperasian program pengolahan data aset komputer harus mengikuti prosedur sebagai berikut :

(1) Pastikan sistem komputer sudah siap dioperasikan dengan benar

(2) Nyalakan komputer sesuai dengan standar yang telah ditentukan

(3) Cari aplikasi pemrograman yang dimaksud, setelah ditemukan klik aplikasi tersebut maka akan keluar tampilan di layar monitor seperti pada gambar dibawah ini :

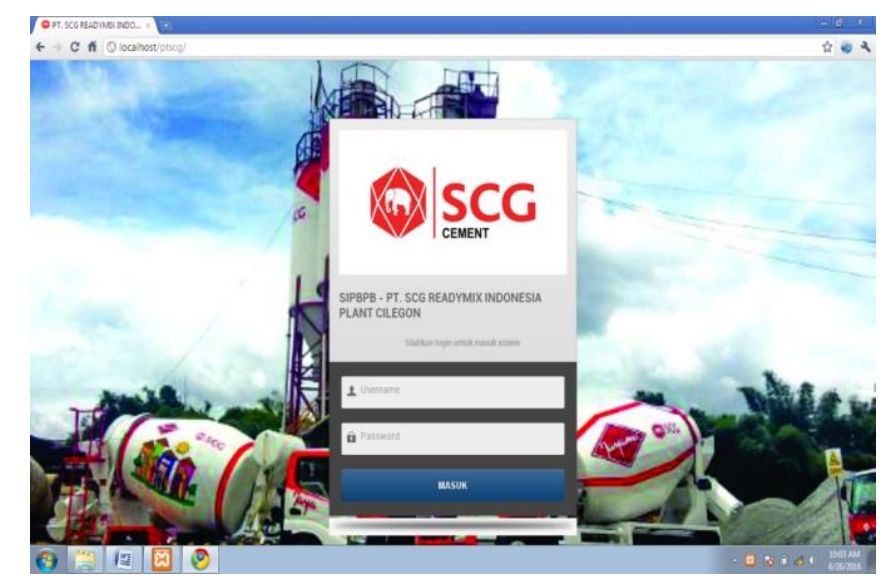

Gambar 9. Tampilan Login Sistem Informasi Pengadaan Bahan Produksi Beton Siap Pakai (Readymix) Pada PT. SCG Readymix Plant Cilegon

Form Login ini merupakan pintu untuk membuka program dan juga untuk keamanan sebuah data yang berada pada program.

\section{Cara masuk aplikasi :}

1. Anda terlebih dahulu memasukan User Klik Enter, kemudian masukan Password Klik Enter. Selanjutnya Klik Login atau Enter.

2. Setelah anda berhasil login maka akan muncul halaman menu seperti pada gambar 10 di bawah.

3. Menu utama merupakan induk dari semua form yang saling berkaitan tanpa menu utama ini maka form-form yang ada tidak bisa di tampilkan. 


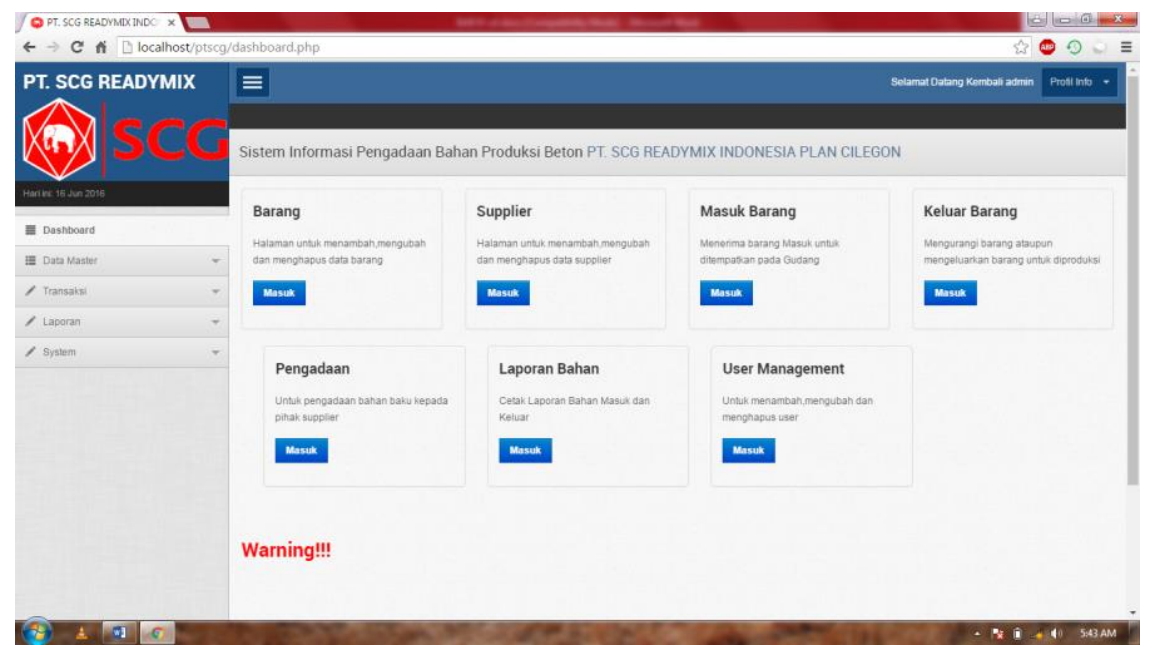

Gambar 10. Tampilan Menu Utama

Di dalam menu utama ini terdiri dari Data Master, Transaksi, Laporan, System dan LogOut. Menu Data Master terdiri dari :

1. Data Barang

2. Data Supplier

\section{Cara Mengisi Master Data Barang}

1. Klik Data Barang

2. Lalu akan muncul form inputan seperti dibawah ini :

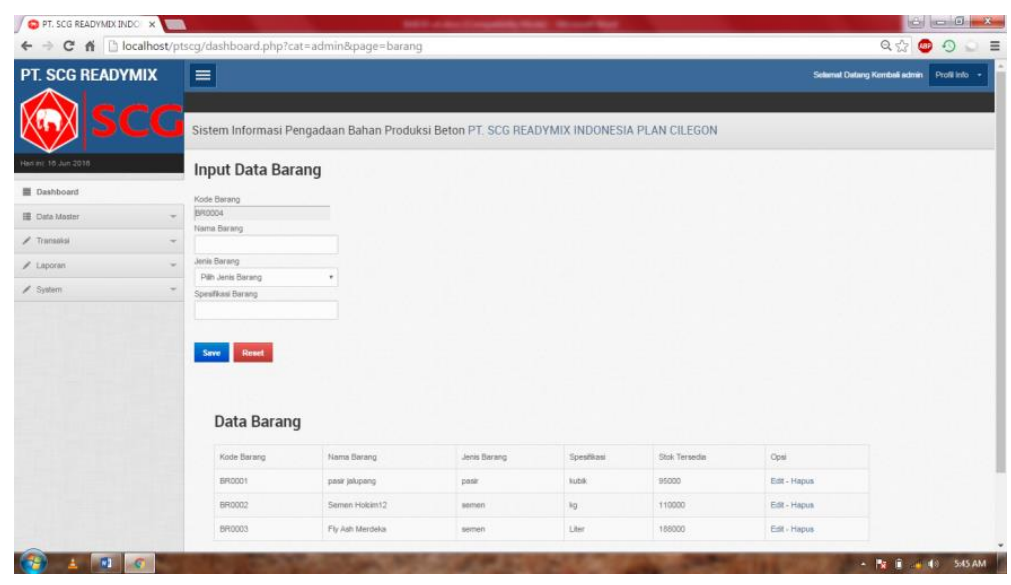

Gambar 11. Input Data Barang

\section{Cara Proses Master Data Barang}

1. Klik Menu Data Master

2. Pilih dan klik Data Barang 
3. Kemudian Input Data Barang

4. Setelah selesai input data Klik Tombol Save

\section{Cara Menginput Master Data Supplier}

1. Klik Data Supplier

2. Lalu akan muncul form inputan seperti dibawah ini :

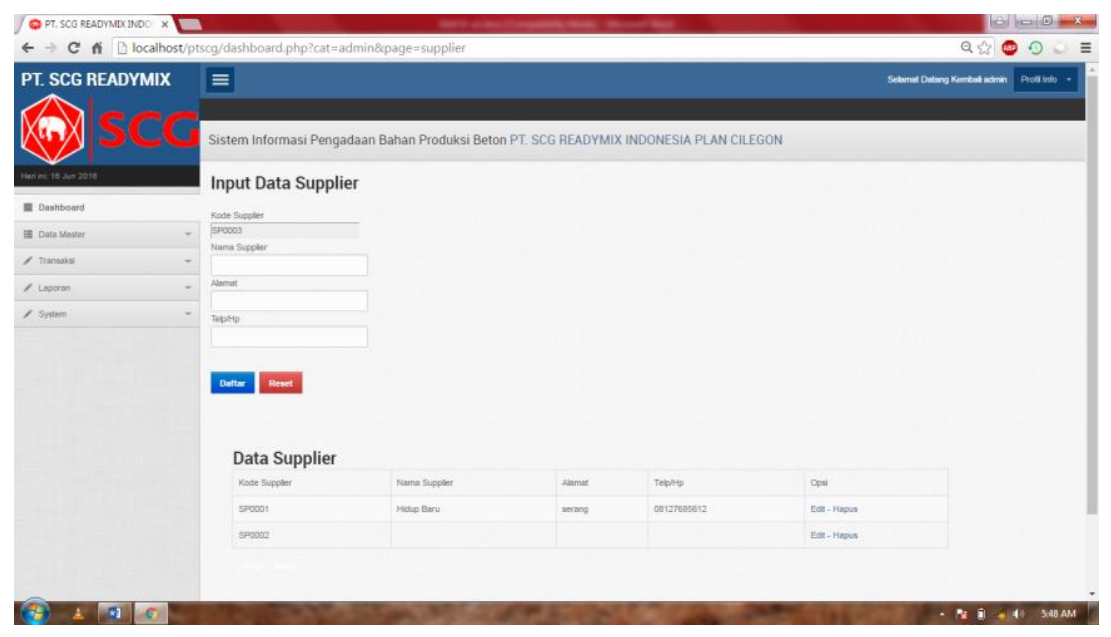

Gambar 12. Input Data Supplier

\section{Cara Proses Master Data Supplier}

1. Klik Menu Data Master

2. Pilih dan klik Data Supplier

3. Kemudian Input Data Supplier

4. Setelah selesai input data Klik Tombol Save

\section{Cara Proses Menu Barang Masuk}

1. Klik Menu Transaksi Pilih Barang Masuk

2. Lalu akan muncul form inputan seperti dibawah ini : 


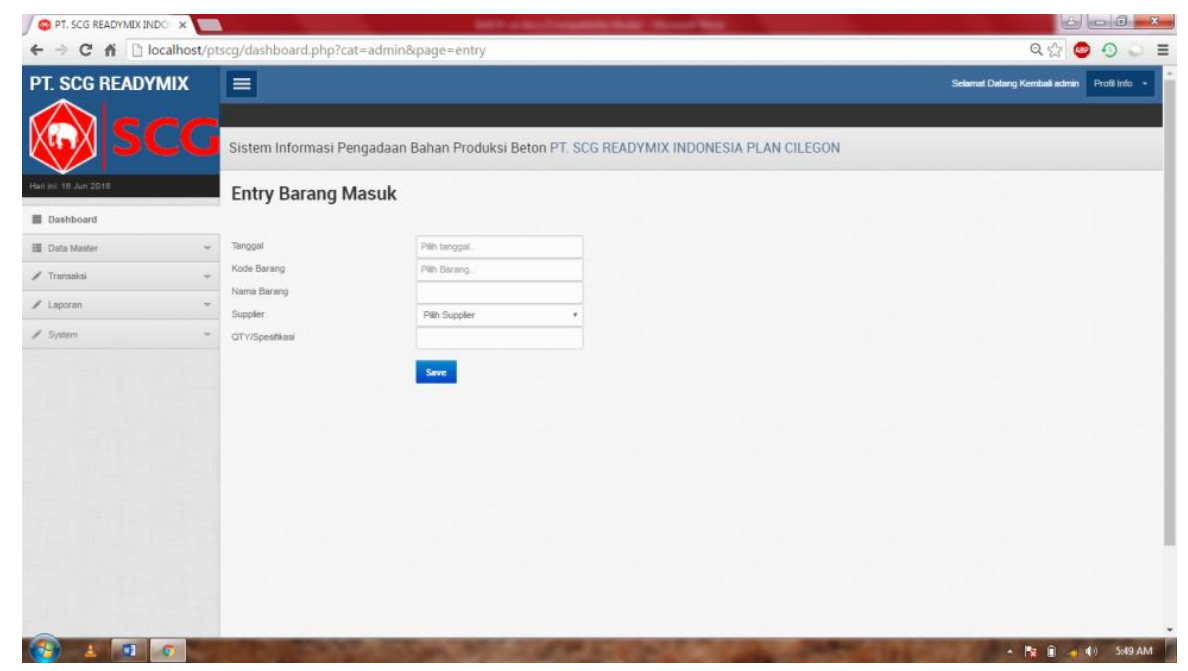

Gambar 13. Input Data Barang Masuk

\section{Cara Menginput Barang Masuk}

1. Klik Menu Transaksi

2. Pilih dan Klik Barang Masuk

3. Kemudian Input Data dan setelah selesai Klik Save

\section{Cara Proses Menu Permintaan Keluar}

1. Klik Menu Transaksi Pilih Pengadaan Bahan

2. Lalu akan muncul form inputan seperti dibawah ini :

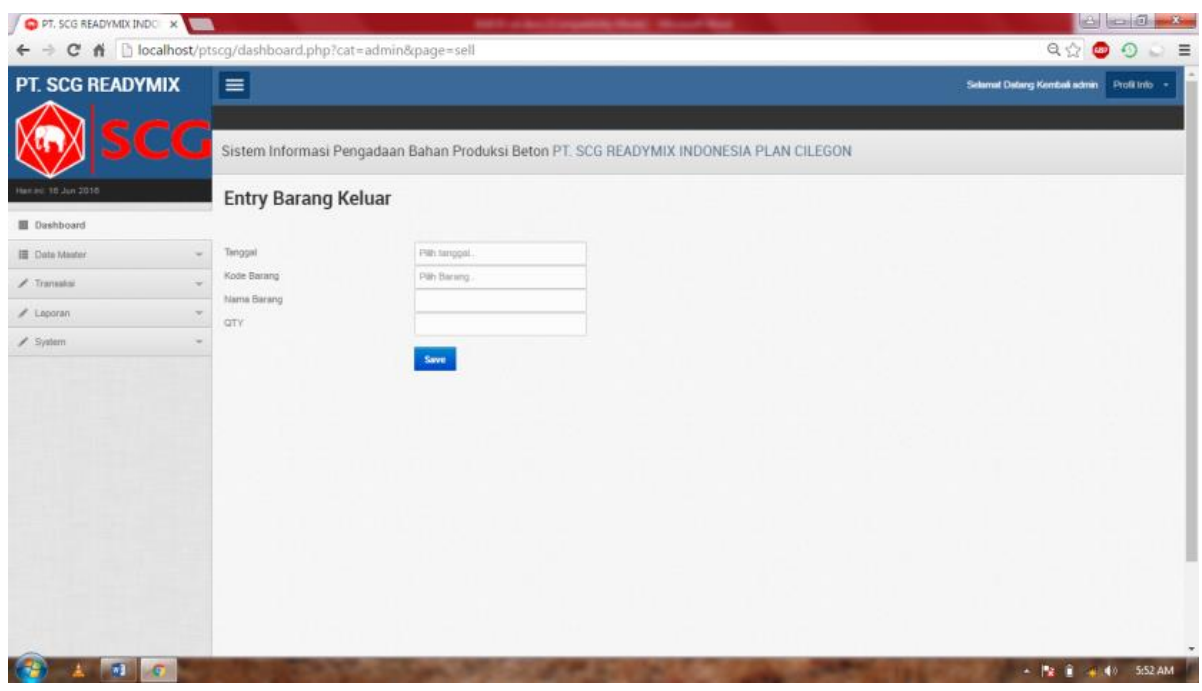

Gambar 14. Input Data Barang Keluar 


\section{KESIMPULAN}

Berdasarkan hasil uraian yang dijelaskan penulis, maka dalam laporan/observasi Sistem Informasi Pengadaan Bahan Produksi Beton Siap Pakai (Readymix) Pada PT. SCG Readymix Indonesia Plant Cilegon dapat disimpulkan sebagai berikut:

1. Dengan adanya Sistem Informasi Pengadaan Bahan Produksi Beton Siap Pakai maka dapat memudahkan pengguna dalam mengelola persediaan bahan produksi agar tidak terjadi kekosongan bahan material pada saat proses produksi.

2. Proses pengecekan persediaan bahan produksi beton siap pakai tidak lagi mengecek ke gudang langsung dan dapat melakukan pendataan dengan baik.

3. Proses pembuatan laporan pengolahan data bahan material berjalan dengan efisien dan efektif selama proses produksi.

\section{REFERENSI}

Achlaq, Mizanul, Moch. 2011. Tugas Dan Tanggung Jawab Pengadaan Barang (Procurement). Jakarta. Salemba.

Ahyari. 2002. Jenis Proses Produksi. Yogyakarta: Prestasi Pustaka Publisher.

Assauri. 2002. Definisi Proses Produksi. Jakarta: PT. Prehallindo Utama.

Fathansyah. 2008. Konsep ERD (Entity Relationship Diagram). Jakarta: PT. Graha Media.

Fathansyah. 2008. Dasar Normalisasi. Jakarta: PT. Graha Media.

Cyscco, R, Dhanny. 2010. Pengertian Bahan Mentah atau Bahan Baku (Raw Materials). Yogyakarta: Andi Offset

Hardjowijono, Budiharjo. 2009. Prinsip Dalam Pengadaan Bahan Produksi. Yogyakarta: Andi Offset.

Hermawan.2008. Proses Pengadaan Barang dan Jasa Berbasis Internet. Bandung: Graha Media.

H. M. Jogiyanto. 2005. Desain Sistem Informasi. Jakarta: Salemba. 
Jurnal Teknik Informatika, Fakultas Teknologi Universitas Al-Azhar. November 2014. Sistem Pengadaan dan Persediaan Bahan Baku Industri Garmen Pada PT. Kencana Lestari: ISSN: 2088-4842.

Jurnal Teknologi Informasi, September 2014. Perancangan Sistem Informasi Pengadaan Barang dan Jasa: ISSN: 2319-8656.

Jurnal Manajemen, Fakultas Ekonomi dan Bisnis Universitas Sam Ratulangi Manado. Januari 2006. Analisa Persediaan Bahan Baku Proses Produksi Ikan Tuna Pada CV. Golden Kaulangan: ISSN: 2303-1174.

Jurnal EMBA, Fakultas Ekonomi dan Bisnis Universitas Sam Ratulangi Manado. September 2014. Penerapan Akuntansi Biaya Pengadaan Bahan Baku Dalam Proses Produksi Pada PT. Putra Karangetang Minahasa Selatan: ISSN: 2303-1174.

Schooner, Christopher. 2008. Pengadaan (Procurement). Jakarta: Salemba

Sugiyono. 2005. Pemrograman Terstruktur. Bandung: Grama Media.

Sukino, Sadano. 2011. Pengertian Kegiatan Proses Produksi. Bandung: Lingga Jaya

Sunarfrihantono, Bimo, 2002. PHP Dan MySQL Untuk Web. Yogyakarta: Andi Offset.

Turban. 2010. Metode Pengadaan Barang (Procurement). Jakarta. Salemba. 